\title{
PENGARUH POROSITAS AGREGAT TERHADAP RONGGA DALAM CAMPURAN BERASPAL PANAS
}

\author{
Muthia Anggraini \\ Program Studi Teknik Sipil Universitas Lancang Kuning \\ Jalan Yos Sudarso Km. 8 Rumbai Pekanbaru \\ E-mail : muthia@unilak.ac.id
}

\begin{abstract}
Abstrak
Semua agregat memiliki pori, porositas agregat akan berbeda antara satu daerah dengan daerah lainnya. Perbedaan ini dapat dilihat dari hasil penyerapan agregat terhadap air. Agregat yang banyak digunakan untuk campuran AC-WC pada proyek pekerjaan jalan skala kecil yang ada di Riau adalah agregat dari quarry Koto Kampar, Ujung Batu, dan Pasir Pengaraian. Porositas agregat yang berbeda akan menghasilkan parameter Marshall yang berbeda pula. Salah satu parameter Marshall adalah rongga dalam campuran atau Void In Mix (VIM). Nilai VIM dalam campuran perkerasan menggambarkan kinerja dari perkerasan tersebut. Tujuan dari penelitian ini untuk mengetahui pengaruh porositas agregat terhadap rongga dalam campuran beraspal panas. Metode yang dilakukan adalah pengujian kadar pori agregat kasar dan halus, serta pengujian marshal. Nilai penyerapan air agregat Pasir Pangaraian adalah 0,635\%, Ujung Batu 1,080\%, dan Kota Kampar 1,125\%. Dari pengujian Marshall didapat nilai VIM untuk agregat Pasir Pangaraian 4,16\%, Ujung Batu 4,36\%, dan Koto Kampar $4,80 \%$. Kesimpulannya semakin kecil nilai penyerapan air agregat maka nilai VIM nya juga akan semakin kecil.
\end{abstract}

Kata Kunci : Agregat, Kadar Pori, Marshall, Nilai VIM

\begin{abstract}
All aggregates have pores, aggregate porosity will be different between one area and another. This difference can be seen from the results of aggregate absorption of water. Aggregates are widely used for mixed AC-WC on a small-scale road works project in Riau is an aggregate of quarry Koto Kampar, Ujung Batu, and Pasir Pengaraian. Different aggregate porosity will produce different Marshall parameters. One of the Marshall parameters is Void In Mix (VIM). VIM value in pavement mix describes the performance of the pavement. The purpose of this research to determine the effect of aggregate porosity on void in mix. The method used is the testing of pore aggregate coarse and fine, and marshall test. The value of water absorption of Pasir Pangaraian aggregate is 0,635\%, Ujung batu 1,080\%, ada Koto kampar 1,125\%. From Marshall test the value VIM Pasir Pangaraian aggregate 4,16\%, Ujung Batu 4,36\%, and Koto kampar 4,80\%. In conclusion the smaller value of aggregate water absorption, the VIM value will also be smaller.
\end{abstract}

Keywords : Aggregate, Pore Content, Marshall, VIM Value 


\section{A. PENDAHULUAN}

Agregat yang ada di alam ini semuanya berpori. Pori agregat berguna untuk menyerap aspal sehingga terjadi ikatan antara aspal dan agregat. Pada Spesifikasi Bina Marga 2010 revisi 3 besarnya absorpsi air dibatasi yaitu maksimum 3\% untuk agregat yang akan digunakan untuk lapisan permukaan dengan pengikat aspal. Terlalu banyak pori dapat mengakibatkan terlalu banyak aspal yang terserap yang berakibat lapisan aspal menjadi tipis, yang berpengaruh terhadap keawetan lapisan aspal.

Agregat yang tersedia di alam mempunyai pori atau rongga udara yang berbeda dari satu quarry dengan quarry lainnya, hal ini dapat dilihat dengan perbedaan nilai resapan air oleh agregat.

Ketiga quarry yang digunakan pada penelitian ini merupakan agregat yang digunakan untuk campuran aspal pada pekerjaan perkerasan jalan yang berada di daerah Riau, yaitu daerah kabupaten yang ada di Riau. Jenis pekerjaan jalan dalam skala kecil, yang masih menggunakan agregat lokal.

Untuk pekerjaan jalan dalam lingkup besar, agregat yang digunakan didatangkan dari daerah Tanjung Pinang Kepulauan Riau. Masih adanya beberapa pihak pelaksana kegiatan yang menggunakan agregat lokal seperti agregat dari quarry Koto Kampar, Ujung Batu, dan Pasir Pengaraian. Menarik minat penulis untuk meneliti tentang agregat lokal tersebut.

Dikaji dari salah satu parameter Marshall yaitu nilai rongga dalam campuran (VIM) dipengaruhi oleh agregat yang digunakan. Void In Mix (VIM) merupakan rongga udara dalam campuran yang terjadi di antara partikel agregat yang terselimuti aspal. VIM diperoleh dari perbandingan berat jenis bulk dengan berat jenis maksimum campuran. VIM yang diperoleh berdasarkan pengujian Marshall harus memenuhi persyaratan sesuai dengan spesifikasi Bina Marga tahun 2010 revisi 3, disyaratkan persentase nilai VIM antara 3,5\% - 5\% untuk campuran beraspal panas jenis Laston (Asphalt Concrete, $A C$ ).

Tujuan penelitian ini adalah untuk mengetahui pengaruh porositas agregat terhadap rongga dalam campuran beraspal panas.

Beberapa penelitian yang sudah ada yaitu Toruan dkk., (2013) melakukan analisis kadar pori pada beberapa lokasi quarry. Anggraini M., (2017), meneliti tentang "Perbandingan Kadar Pori Agregat Campuran AC-WC Sebelum dan Setelah Ekstraksi. Rondonumu dkk., (2013), meneliti tentang "Pengaruh Sifat Fisik Agregat Terhadap Rongga Dalam Campuran Beraspal Panas. Anggraini M., (2017), meneliti tentang "Comparison Pore Aggregate Levels After Extraction With Solvents Pertamax Plus and Gasoline". Laoli dkk., (2013) melakukan analisis Kajian Penyebab Perbedaan Nilai Berat Jenis Maksimum Campuran Beraspal Panas Yang Dihitung Berdasarkan Metode Marshall Dengan Yang Dicari Langsung Berdasarkan AASTHO T209.

\section{B. TINJAUAN PUSTAKA}

\section{Metode Pengujian Berat Jenis dan Penyerapan Air Agregat Kasar}

Pengujian berat jenis agregat kasar dilaksanakan dengan mengikuti Standar Nasional Indonesia, Metode Pengujian Berat Jenis dan Penyerapan Air Agregat Kasar menggunakan SNI 03-1969-2008. Cara menghitungnya adalah :

a. Berat Jenis Curah (Bulk Specific Gravity)

Berat jenis dengan memperhitungkan berat agregat 
kering dan seluruh volume agregat, dengan menggunakan persamaan :

$\mathrm{Sd}=\frac{\mathrm{A}}{(\mathrm{B}-\mathrm{C})}$

Dengan :

$$
\begin{aligned}
\mathrm{Sd}= & \text { Berat jenis curah } \\
\mathrm{A}= & \text { Berat benda uji kering } \\
& \text { oven (gram) } \\
\mathrm{B}= & \text { Berat benda uji } \\
& \text { kondisi jenuh kering } \\
& \text { permukaan (gram) } \\
\mathrm{C}= & \begin{array}{l}
\text { Berat benda uji dalam } \\
\text { air (gram) }
\end{array}
\end{aligned}
$$

b. Periode pengeringan permukaan tak jenuh (Saturated Surface Dry)

Berat jenis dengan memperhitungkan berat agregat dalam keadaan kering permukaan dan seluruh volume agregat, dengan menggunakan persamaan :

Ss $\quad=\frac{\mathrm{B}}{(\mathrm{B}-\mathrm{C})}$

Dengan :

$$
\begin{aligned}
& \mathrm{Ss}= \begin{array}{l}
\text { Berat jenis kering } \\
\text { permukaan jenuh }
\end{array} \\
& \mathrm{B}= \begin{array}{l}
\text { Berat benda uji jenuh } \\
\text { kering permukaan } \\
\end{array} \\
&\mathrm{(gram}) \\
& \mathrm{C}=
\end{aligned}
$$

c. Berat Jenis Semu (Apparent Specific Gravity)

Berat jenis dengan memperhitungkan berat agregat dalam keadaan kering dan seluruh volume agregat yang tidak dapat diresapi oleh air, dengan menggunakan persamaan :

$\mathrm{Sa}=\frac{\mathrm{A}}{(\mathrm{A}-\mathrm{C})}$

Dengan :
$\mathrm{Sa}=$ Berat jenis semu

A $\quad=$ Berat benda uji kering oven (gram)

$\mathrm{C}=$ Berat benda uji dalam air (gram)

d. Penyerapan Air

Penyerapan merupakan persentase berat air yang dapat diserap pori terhadap berat agregat kering, dengan menggunakan persamaan :

$$
\mathrm{Sw}=\left[\frac{\mathrm{B}-\mathrm{A}}{\mathrm{A}}\right] \times 100 \%
$$

Dengan :

$$
\begin{aligned}
\mathrm{Sw}= & \text { Penyerapan air } \\
\mathrm{A}= & \text { Berat benda uji kering } \\
\mathrm{B}= & \text { oven (gram) } \\
& \text { Berat benda uji } \\
& \text { kondisi jenuh kering } \\
& \text { permukaan (gram) }
\end{aligned}
$$

\section{Metode Pengujian Berat Jenis dan Penyerapan Air Agregat Halus}

Untuk Pengujian Berat Jenis dan Penyerapan Air Agregat Halus menggunakan SNI 03-1970-2008. Untuk menghitungnya adalah :

a. Berat Jenis Curah Kering ( $S d)$

$$
S d \quad=\frac{A}{(B+S-C)}
$$

$$
\begin{aligned}
\text { Dengan : } & \\
\mathrm{A}= & \text { Berat benda uji kering } \\
& \text { oven (gram) } \\
\mathrm{B}= & \text { Berat piknometer } \\
& \text { yang berisi air (gram) } \\
\mathrm{C}= & \text { Berat piknometer } \\
& \text { dengan benda uji dan } \\
& \text { air sampai batas } \\
& \text { pembacaan (gram) } \\
= & \text { Berat benda uji } \\
& \text { kondisi jenuh kering } \\
& \text { permukaan (gram) }
\end{aligned}
$$


b. Berat Jenis Kering Permukaan $(S s)$

$$
\text { Ss } \quad=\frac{\mathrm{S}}{(\mathrm{B}+\mathrm{S}-\mathrm{C})}
$$

\section{Dengan :}

$$
\begin{aligned}
\mathrm{S}= & \begin{array}{l}
\text { Berat benda uji } \\
\text { kondisi jenuh kering } \\
\text { permukaan (gram) }
\end{array} \\
\mathrm{A}= & \begin{array}{l}
\text { Berat benda uji kering } \\
\text { oven (gram) }
\end{array} \\
\mathrm{B}= & \text { Berat piknometer } \\
& \text { yang berisi air (gram) } \\
\mathrm{C}= & \begin{array}{l}
\text { Berat piknometer } \\
\text { dengan benda uji dan } \\
\text { air sampai batas } \\
\text { pembacaan (gram) }
\end{array}
\end{aligned}
$$

c. Berat Jenis Semu $(\mathrm{Sa})$

$$
\mathrm{Sa}=\frac{\mathrm{A}}{(\mathrm{B}+\mathrm{A}-\mathrm{C})}
$$

Dengan :

$$
\begin{aligned}
\mathrm{A}= & \begin{array}{l}
\text { Berat benda uji kering } \\
\text { oven (gram) }
\end{array} \\
\mathrm{B}= & \begin{array}{l}
\text { Berat piknometer } \\
\text { yang berisi air (gram) }
\end{array} \\
\mathrm{C}= & \begin{array}{l}
\text { Berat piknometer } \\
\text { dengan benda uji dan }
\end{array} \\
& \text { air sampai batas } \\
& \text { pembacaan (gram) } \\
\mathrm{C}= & \begin{array}{l}
\text { Berat piknometer } \\
\text { dengan benda uji dan }
\end{array} \\
& \begin{array}{l}
\text { air sampai batas } \\
\text { pembacaan (gram) }
\end{array}
\end{aligned}
$$

d. Penyerapan Air (Sw)

$$
\mathrm{Sw}=\left[\frac{\mathrm{S}-\mathrm{A}}{\mathrm{A}}\right] \times 100 \%
$$

$$
\begin{aligned}
\text { Dengan : } & \\
\mathrm{A}= & \text { Berat benda uji kering } \\
& \text { oven }(\text { gram }) \\
\mathrm{S}= & \text { Berat benda uji } \\
& \text { kondisi jenuh kering } \\
& \text { permukaan (gram) }
\end{aligned}
$$

\section{Porositas Agregat}

Semua agregat adalah porus. Keporusan agregat menentukan banyaknya zat cair yang dapat diserap oleh agregat. Kemampuan agregat untuk menyerap air (aspal) adalah suatu informasi yang penting yang harus diketahui dalam pembuatan campuran beraspal. Jika daya serap agregat sangat tinggi, agregat ini akan terus menyerap aspal baik pada saat maupun setelah proses pencampuran agregat. Hal ini akan menyebabkan aspal yang berada di permukaan agregat yang berguna untuk mengikat partikel agregat menjadi lebih sedikit sehingga akan menghasilkan film aspal yang tipis (Toruan, 2013). yaitu :

Agregat terdiri dari 2 (dua) bagian

a. Bagian padat (solid)

Bagian padat terdiri dari partikelpartikel padat

b. Bagian rongga (void)

Bagian berongga terisi oleh air dan udara

Dalam campuran beraspal panas agregat dan aspal dicampur dalam keadaan panas maka air yang terdapat dalam agregat dianggap tidak ada. Porositas agregat umumnya ditandai dengan jumlah air yang dapat diserap oleh agregat ketika direndam dalam air.

\section{Rongga Dalam Campuran (VIM)}

Vix In Mix (VIM) yaitu volume pori yang masih tersisa setelah campuran beton aspal dipadatkan. Nilai VIM yang terlalu besar akan mengakibatkan beton aspal berkurang kekedapan airnya, sehingga berakibat meningkatnya proses oksidasi aspal yang dapat mempercepat penuaan aspal. Sedangkan jika nilai VIM terlalu kecil akan mengakibatkan perkerasan 
mengalami bleeding jika temperatur meningkat. VIM dinyatakan dalam persen terhadap volume total campuran. Berdasarkan definisi tersebut, maka:

$$
\mathrm{VIM}=\frac{v_{\text {udara }}}{v_{\text {total }}} \times 100
$$

Atau :

$$
\mathrm{VIM}=100\left(1-\frac{\mathrm{G}_{\mathrm{mb}}}{\mathrm{G}_{\mathrm{mm}}}\right)
$$

Atau :

$$
\mathrm{VIM}=100 \% \times\left(\frac{\mathrm{G}_{\mathrm{mm}}-\mathrm{G}_{\mathrm{mb}}}{\mathrm{G}_{\mathrm{mm}}}\right)
$$

Dengan :

$$
\begin{aligned}
\mathrm{VIM}= & \begin{array}{l}
\text { Rongga udara campuran, } \\
\end{array} \\
& \begin{array}{l}
\text { campuran }) \\
\mathrm{G} \text { terhadap total }
\end{array} \\
\mathrm{G}_{\mathrm{mb}}= & \begin{array}{l}
\text { Berat jenis bulk } \\
\text { campuran padat }
\end{array} \\
\mathrm{G}_{\mathrm{mm}}= & \begin{array}{l}
\text { Berat jenis maksimum } \\
\text { teoritis campuran }
\end{array}
\end{aligned}
$$

\section{Aspal}

Aspal yang dipergunakan sebagai material perkerasan jalan berfungsi sebagaiberikut :

a. Bahan pengikat, memberikan ikatan yang kuat antara aspal dan agregat dan sesama aspal.

b. Bahan pengisi, mengisi rongga antar butir agregat dan pori-pori yang ada dalam butir agregat itu sendiri.

Fungsi utama aspal untuk kedua jenis proses pembentukan perkerasan yaitu proses pencampuran prahampar dan pascahampar itu berbeda. Pada proses prahampar aspal yang dicampur dengan agregat akan membungkus atau menyelimuti butir-butir agregat, mengisi pori antar butir, dan meresap kedalam pori masing-masing butir.

\section{DATA DAN ANALISA DATA}

Penelitian dilakukan dengan pengujian di laboratorium. Mengacu kepada pengujian Berat Jenis dan Penyerapan Air Agregat Kasar menggunakan SNI 03-1969-2008 dan Pengujian Berat Jenis dan Penyerapan Air Agregat Halus menggunakan SNI 03-1970-2008. Pengujian marshal untuk mendapatkan nilai VIM. Pengujian dilakukan dengan cara mengambil data langsung di lapangan (data primer) yang berupa sampel agregat dari quarry Koto Kampar, Ujung Batu, dan Pasir Pengaraian. Bahan yang digunakan adalah campuran aspal mix design dari (Asphalt Mixing Plant), agregat dari quarry Koto Kampar, Ujung Batu, dan Pasir Pengaraian. Campuran aspal yang digunakan dalam penelitian ini campuran Asphalt Concrete Wearing Course.

\section{HASIL DAN PEMBAHASAN}

\section{Hasil Pemeriksaan Agregat Dari Quarry Koto Kampar, Ujung Batu, dan Pasir Pengaraian}

Pengujian awal agregat yaitu pengujian keausan (abrasi) agregat dari masing-masing quarry. Hasilnya dapat di lihat pada Tabel 1.

Tabel 1. Hasil Pemeriksaan Awal Agregat

\begin{tabular}{l|lcc}
\hline No & $\begin{array}{c}\text { Agregat Kasar } \\
\text { Quarry }\end{array}$ & $\begin{array}{c}\text { Nilai Abrasi } \\
\text { (Keausan) } \\
\text { \% }\end{array}$ & $\begin{array}{c}\text { Syarat Spek. } \\
\text { Maks (\%) }\end{array}$ \\
\hline 1. & Pasir Pangaraian & 30,58 & 40 \\
2. & Ujung Batu & 34,58 & 40 \\
3. & Koto Kampar & 36,20 & 40 \\
\hline
\end{tabular}


Nilai abrasi agregat terkecil yaitu agregat kasar dari quarry Pasir Pangaraian, dan yang terkecil dari quarry Koto Kampar. Nilai abrasi yang besar mengindikasikan rongga dalam agregat yang cukup banyak sehingga penyerapannya juga semakin tinggi (Arifin dkk., 2007).

Dari hasil pengujian laboratorium pengujian kadar pori agregat kasar dan halus masing-masing quarry maka didapat nilai berat jenis dan penyerapannya untuk quarry Koto Kampar dapat dilihat pada Tabel 2. Dari Tabel 2 dapat dilihat bahwa kadar pori untuk agregat kasar (coarse agregat) adalah $1,186 \%$, untuk medium agregat $1,629 \%$, untuk abu batu $0,756 \%$, dan untuk pasir nilainya $0,796 \%$. Hasil yang didapat memenuhi batasan spesifikasi yaitu maksimal $3 \%$.

Penyerapan air total agregat dalam campuran quarry Koto Kampar dapat dilihat pada Tabel 3.

Tabel 2. Hasil Pengujian Kadar Pori Agregat Quarry Koto Kampar

\begin{tabular}{lccccc}
\hline \multicolumn{1}{c}{ Pengujian } & $\begin{array}{c}\text { Agregat } \\
\text { Kasar }\end{array}$ & $\begin{array}{c}\text { Agregat } \\
\text { Sedang }\end{array}$ & $\begin{array}{c}\text { Abu } \\
\text { Batu }\end{array}$ & Pasir & Spek. \\
\hline BJ Bulk (Sd) & 2,574 & 2,543 & 2,597 & 2,570 & \\
BJ SSD (Ss) & 2,604 & 2,585 & 2,617 & 2,590 & \\
BJ Semu (Sa) & 2,655 & 2,653 & 2,650 & 2,623 & \\
Penyerapan Air (Sw) & 1,186 & 1,629 & 0,756 & 0,796 & Maks. 3\% \\
\hline
\end{tabular}

Tabel 3. Resapan Air Total dalam Campuran Quarry Koto Kampar

\begin{tabular}{c|cccc}
\hline No & Jenis Agregat & $\begin{array}{c}\text { Penyerapan } \\
\text { air } \\
(\boldsymbol{\%})\end{array}$ & $\begin{array}{c}\text { Proporsi Agregat } \\
\text { Dalam } \\
\text { Campuran } \\
\mathbf{( \% )}\end{array}$ & $\begin{array}{c}\text { Penyerapan } \\
\text { Air Dalam } \\
\text { Campuran } \\
(\boldsymbol{\%})\end{array}$ \\
\hline 1 & Agregat Kasar & 1,186 & 16 & 0,190 \\
2 & Agregat Halus & 1,629 & 35 & 0,570 \\
3 & Abu Batu & 0,756 & 35 & 0,265 \\
4 & Pasir & 0,796 & 12,50 & 0,099 \\
\hline \multicolumn{2}{l}{ Penyerapan Air Total Dalam Campuran (\%) } & 1,125 \\
\hline
\end{tabular}

Pada Tabel 3 terlihat bahwa penyerapan air total dalam campuran adalah $1,125 \%$. Nilainya masih memenuhi batas toleransi spesifikasi 2010 revisi 3 adalah maksimum 3\%.

Nilai berat jenis dan penyerapannya untuk quarry Ujung Batu dapat dilihat pada Tabel 4. Dari Tabel 4 dapat dilihat bahwa kadar pori untuk agregat kasar (coarse agregat) adalah $0,800 \%$, untuk medium agregat $1,521 \%$, untuk abu batu $0,918 \%$, dan untuk pasir nilainya $0,796 \%$. Hasil yang didapat memenuhi batasan spesifikasi yaitu maksimal 3\%.

Penyerapan air total agregat dalam campuran quarry Ujung Batu dapat dilihat pada Tabel 5.

Tabel 4. Hasil Pengujian Kadar Pori Agregat Quarry Ujung Batu

\begin{tabular}{lccccc}
\hline \multicolumn{1}{c}{ Pengujian } & $\begin{array}{c}\text { Agregat } \\
\text { Kasar }\end{array}$ & $\begin{array}{c}\text { Agregat } \\
\text { Sedang }\end{array}$ & $\begin{array}{c}\text { Abu } \\
\text { Batu }\end{array}$ & Pasir & Spek. \\
\hline BJ Bulk (Sd) & 2,576 & 2,540 & 2,575 & 2,570 & \\
BJ SSD (Ss) & 2,597 & 2,579 & 2,604 & 2,590 & \\
BJ Semu (Sa) & 2,630 & 2,642 & 2,651 & 2,623 & \\
Penyerapan Air (Sw) & 0,800 & 1,521 & 0,918 & 0,796 & Maks. 3\% \\
\hline
\end{tabular}


Tabel 5. Resapan Air Total dalam Campuran Quarry Ujung Batu

\begin{tabular}{clccc} 
No & Jenis Agregat & $\begin{array}{c}\text { Penyerapan } \\
\text { air } \\
(\boldsymbol{\%})\end{array}$ & $\begin{array}{c}\text { Proporsi Agregat } \\
\text { Dalam } \\
\text { Campuran } \\
(\boldsymbol{\%})\end{array}$ & $\begin{array}{c}\text { Penyerapan } \\
\text { Air Dalam } \\
\text { Campuran } \\
(\mathbf{\%})\end{array}$ \\
\hline 1 & Agregat Kasar & 0,800 & 16 & 0,128 \\
2 & Agregat Halus & 1,521 & 35 & 0,532 \\
3 & Abu Batu & 0,918 & 35 & 0,321 \\
4 & Pasir & 0,796 & 12,50 & 0,099 \\
\hline \multicolumn{2}{l}{ Penyerapan Air Total Dalam Campuran (\%) } & 1,080 \\
\hline
\end{tabular}

Pada Tabel 5 terlihat bahwa penyerapan air total dalam campuran adalah $1,080 \%$. Nilainya masih memenuhi batas toleransi spesifikasi 2010 revisi 3 adalah maksimum 3\%.

Nilai berat jenis dan penyerapannya untuk quarry Pasir Pangaraian dapat dilihat pada Tabel 6 . Dari Tabel 6 dapat dilihat bahwa kadar pori untuk agregat kasar (coarse agregat) adalah 0,797\%, untuk medium agregat $0,584 \%$, untuk abu batu
$0,654 \%$, dan untuk pasir nilainya $0,594 \%$. Hasil yang didapat memenuhi batasan spesifikasi yaitu maksimal $3 \%$.

Penyerapan air total agregat dalam campuran quarry Pasir Pangaraian dapat dilihat pada Tabel 7. Pada Tabel 7 terlihat bahwa penyerapan air total dalam campuran adalah 0,635\% . Nilainya masih memenuhi batas toleransi spesifikasi 2010 revisi 3 adalah maksimum $3 \%$.

Tabel 6. Hasil Pengujian Kadar Pori Agregat Quarry Pasir Pangaraian

\begin{tabular}{lccccc}
\hline \multicolumn{1}{c}{ Pengujian } & $\begin{array}{c}\text { Agregat } \\
\text { Kasar }\end{array}$ & $\begin{array}{c}\text { Agregat } \\
\text { Sedang }\end{array}$ & $\begin{array}{c}\text { Abu } \\
\text { Batu }\end{array}$ & Pasir & Spek. \\
\hline BJ Bulk (Sd) & 2,606 & 2,614 & 2,600 & 2,575 & \\
BJ SSD (Ss) & 2,627 & 2,629 & 2,617 & 2,590 & \\
BJ Semu (Sa) & 2,661 & 2,655 & 2,645 & 2,615 & \\
Penyerapan Air (Sw) & 0,797 & 0,584 & 0,654 & 0,594 & Maks. 3\% \\
\hline
\end{tabular}

Tabel 7. Resapan Air Total dalam Campuran Quarry Pasir Pangaraian

\begin{tabular}{|c|c|c|c|c|}
\hline No & Jenis Agregat & $\begin{array}{c}\text { Penyerapan } \\
\text { air } \\
(\%)\end{array}$ & $\begin{array}{c}\text { Proporsi Agregat } \\
\text { Dalam } \\
\text { Campuran } \\
(\%)\end{array}$ & $\begin{array}{c}\text { Penyerapan } \\
\text { Air Dalam } \\
\text { Campuran } \\
(\%)\end{array}$ \\
\hline 1 & Agregat Kasar & 0,797 & 16 & 0,128 \\
\hline 2 & Agregat Halus & 0,584 & 35 & 0,204 \\
\hline 3 & Abu Batu & 0,654 & 35 & 0,229 \\
\hline 4 & Pasir & 0,594 & 12,50 & 0,074 \\
\hline \multicolumn{4}{|c|}{ Penyerapan Air Total Dalam Campuran (\%) } & 0,635 \\
\hline
\end{tabular}

Perbandingan penyerapan air untuk quarry Koto Kampar, Ujung Batu, dan Pasir Pangaraian dapat dilihat pada Tabel 8.

Dari 3 (tiga) quarry yaitu agregat dari Kota Kampar, Ujung Batu, dan
Pasir Pangaraian didapat nilai penyerapan air agregat dalam campuran yang terkecil adalah agregat dari quarry Pasir Pangaraian yaitu $0,635 \%$ dan yang terbesar agregat dari quarry Koto Kampar yaitu $1,125 \%$. 
Tabel 8. Rekapitulasi Penyerapan Air Agregat Dalam Campuran

\begin{tabular}{clc|c}
\hline No & Quarry Agregat & $\begin{array}{c}\text { Penyerapan air agregat } \\
\text { dalam campuran (\%) }\end{array}$ & $\begin{array}{c}\text { Syarat Spek } \\
\text { Maks. (\%) }\end{array}$ \\
\hline 1 & Pasir Pangaraian & 0,635 & 3 \\
2 & Ujung Batu & 1,080 & 3 \\
3 & Koto Kampar & 1,125 & 3 \\
\hline
\end{tabular}

\section{Hasil Pemeriksaan Marshall}

Pengujian laboratorium parameter Marshall campuran beraspal terhadap 3 quarry ditinjau dari nilai VIM dapat dilihat pada Tabel 9.

Hubungan sifat fisik agregat dengan parameter Marshall ditinjau dari nilai VIM dapat dilihat pada Tabel 10.

Dari Tabel 10 dapat dilihat bahwa pengaruh porositas atau penyerapan agregat terhadap nilai VIM adalah semakin kecil nilai penyerapan air agregat maka nilai VIM semakin rendah. Sesuai dengan penelitian Rondonuwu dkk., (2013), menyarankan dalam campuran beraspal panas untuk menggunakan material dengan nilai keuasan agregat dan penyerapan air relatif kecil.

Tabel 9. Rekapitulasi Hasil Pengujian Marshall Ditinjau dari Nilai VIM

\begin{tabular}{lccc}
\hline Quarry Agregat & $\begin{array}{c}\text { Berat Jenis } \\
\text { Maksimum }\end{array}$ & $\begin{array}{c}\text { Berat Jenis Bulk } \\
\text { Campuran }\end{array}$ & VIM (\%) \\
\hline Pasir Pangaraian & 2,424 & 2,323 & 4,16 \\
Ujung Batu & 2,405 & 2,300 & 4,36 \\
Koto Kampar & 2,395 & 2,280 & 4,80 \\
\hline
\end{tabular}

Tabel 10. Rekapitulasi Sifat Fisik Agregat dengan Parameter Marshall Ditinjau dari Nilai VIM

\begin{tabular}{cllcc}
\hline No & Quarry Agregat & $\begin{array}{c}\text { Penyerapan air } \\
\text { (rata-rata) }\end{array}$ & VIM (\%) \\
\hline 1 & Pasir Pangaraian & 0,635 & 4,16 \\
2 & Ujung Batu & 1,080 & 4,36 \\
3 & Koto Kampar & 1,125 & 4,80 \\
\hline
\end{tabular}

\section{E. KESIMPULAN}

Berdasarkan hasil penelitian diperoleh kesimpulan yaitu pengaruh porositas atau penyerapan agregat terhadap nilai VIM adalah semakin kecil nilai penyerapan air agregat maka nilai VIM semakin rendah.

\section{DAFTAR PUSTAKA}

Anggraini M., 2017, Perbandingan Kadar Pori Agregat Campuran AC-WC Sebelumdan Setelah Ektraksi, Konferensi Nasional Teknik sipil (KNTSP) 2017, ISBN : 978-602-61059-0-5.
Anggraini M., 2017, Comparison Pore Aggregat Levels After Extraction With Solvents Pertamax Plus and Gasoline, IOP Conference Series: Earth and Environmental Sciene 97 (1), 012020.

Arifin S., Kasan M., dan Pradani N., 2007, Pengaruh Nilai Abrasi Agregat Terhadap Karakteristik Beton Aspal, Jurnal SMARTek, Volume 5, Nomor $1: 1$ - 11.

Departemen Pekerjaan Umum, 2008, Standar Nasional Indonesia Cara Uji Berat Jenis dan Penyerapan Air Agregat Kasar SNI 1969-2008, Bandung. 
Departemen Pekerjaan Umum, 2008, Standar Nasional Indonesia Cara Uji Berat Jenis dan Penyerapan Air Agregat Halus SNI 19702008, Bandung.

Direktorat Jenderal Bina Marga, 2010, Spesifikasi Umum Binamarga 2010 Revisi 3, Kementrian Pekerjaan Umum Direktorat Jenderal Bina Marga, Jakarta.
Rondonuwu F., Kaseke HO., Rumayar ELA., Manopo ERM., Pengaruh Sifat Fisik Agregat Terhadap Rongga Dalam Campuran Beraspal Panas, Jurnal Sipil Statik, Volume 1, Nomor 3.

Toruan LA., Kaseke HO., Kereh FL., dan Sendow TK., 2013, Pengaruh Porositas Agregat Terhadap Berat Jenis Maksimum Campuran, Jurnal Sipil Statik, Volume 1, Nomor 3. 